\title{
ПОЧЕМУ ИЩУТ СМЫСЛ В БЕССМЫСЛИЦЕ? (КРУЧЕНЫХ И ХОМСКИЙ КАК НЕВОЛЬНЫЕ ТВОРЦЫ СМЫСЛА)
}

\section{WHY DO THEY LOOK FOR MEANING IN NONSENSE? (KRUCHENYKH AND CHOMSKY AS UNWITTING CREATORS OF MEANING)}

\section{S. Kleckaja}

Summary: The article analyzes the practice of interpreting statements that are initially stated by their authors as meaningless. Such interpretive behavior is a side effect of the presumption of meaningfulness, which usually protects the interpreter from mistakenly recognizing a statement that is not meaningless. It is concluded that in the interpretation of meaningless statements, the mechanisms characteristic of any interpretative activity are manifested. One of these mechanisms is the reconstruction of the context in which the statement could be meaningful, appropriate, or at least possible. The specificity of the interpretation of obviously meaningless utterances is that the reconstructed context is hypothetical, that is, it denies both the real context of the meaningless utterance and the intentions of its author.

Keywords: absurd, nonsense, interpretation, Kruchenykh, Chomsky, presumption of sense.
Клецкая Светлана Ильинична

К.филол.н., доцент, Южный федеральный университет (Ростов-на-Дону)

kleckaja@inbox.ru

Аннотация: В статье анализируется практика интерпретации высказываний, которые изначально заявлены их авторами как бессмысленные. Такое интерпретативное поведение представляет собой побочный эффект презумпции осмысленности, в обычном случае предохраняющей интерпретатора от ошибочного признания бессмысленным высказывания, которое таковым не является. Делается вывод, что в интерпретации бессмысленных высказываний проявляются механизмы, характерные для любой интерпретационной активности. Одним из таких механизмов является реконструкция контекста, в котором высказывание могло бы осмысленным, уместным или хотя бы возможным. Специфика интерпретации заведомо бессмысленных высказываний состоит в том, что реконструируемый контекст является гипотетическим, то есть отрицающим как реальный контекст бессмысленного высказывания, так и намерения его автора.

Ключевые слова: абсурд, бессмыслица, интерпретация, Крученых, Хомский, презумпция осмысленности.
B ессмысленные, абсурдные высказывания и тексты (языковой нонсенс) уже достаточно давно стали объектом внимания лингвистов, философов, логиков, литературоведов. Набор аспектов, в которых такие высказывания могут рассматриваться, чрезвычайно широк: это механизмы, в силу нарушения которых высказывание оказывается бессмысленным [1; 2], степени бессмысленности [20; 21], социальные [23] и эстетические функции бессмысленных высказываний (ср. публикации, посвященные литературе нонсенса, театру абсурда, творчеству ОБЭРИУ [10; 22]).

Бессмысленные высказывания становятся объектом лингвистического анализа прежде всего в плане формальных и смысловых структурных свойств. Это означает, что такие высказывания становятся объектом применения стандартных интерпретативных процедур. Обычно применение этих процедур оказывается безуспешным, а бессмысленные предложения используются в качестве «отрицательного языкового материала». Однако этот вариант не является универсальным. В этом отношении заслуживают внимания факты интерпретации высказываний, которые заведомо создаются как высказывания бессмысленные, но становятся объектом полноценной интерпретации.
Ярким примером являются интерпретации начальной строки стихотворения А. Крученых «дыр бул щыл...». В связи со этим примером обратим внимание, что интерпретации, предлагаемые исследователями, противоречат автоинтерпретациям самого автора. В частности, уже первая публикация цикла из пяти стихотворений сопровождалась комментарием: «Три стихотворения, написанные на собственном языке. От других отличается: слова его не имеют определенного значения» [5, с. 27], а сам Крученых впоследствии указывал, что ключом к строкам «дыр бул щыл» является русская фонетика в ее специфичных чертах (подробнее см. нашу статью [3]). Тем не менее, стихотворения Крученых неоднократно получали семантическую интерпретацию и осмыслялись его интерпретаторами как звукопись или звукоподражание, через интертекстуальные связи, через модель метаплазма, то есть модификации плана выражения, и даже как шифр (подробный обзор см. в нашей статье [4]).

Аналогичную реакцию мы обнаруживаем и в интерпретациях фразы Н. Хомского Colorless green ideas sleep furiously ('Бесцветные зеленые идеи яростно спят') [12, с. 138]. Н. Хомский намеренно создал эту фразу в качестве иллюстрации грамматичного, но лишенного смысла высказывания. Однако в значительном ряде работ выска- 
зывается несогласие с тем, что данная фраза является полностью бессмысленной, и предлагаются контексты, в которых она могла бы быть уместной и претендовать на выражение некоторого смысла. Самой популярной является версия поэтического или, шире, метафорического, образного контекста (см., например, работы [6; 9; 14]), которая к тому же была реализована практически в написании стихотворений, содержащих эту фразу (примеры приводятся в статье [18, р. 57-59]). Дальше всех пошел, пожалуй, М. Фуко, предложивший четыре контекста, в которых данное высказывание является приемлемым: эта фраза «лишена смысла только в том случае, если... признать, что речь идет не об описании сна, поэтическом тексте, зашифрованном послании или словах наркомана» $[11$, с. 91].

Стоит обратить внимание на то, что все интерпретации фразы Хомского опираются на поиск гипотетического контекста, в котором такая фраза могла бы появиться и иметь смысл. Такой подход явно противоречит реальному положению: фраза Хомского - это пример, придуманный лингвистом, чтобы проиллюстрировать возможность существования грамматичных, но бессмысленных фраз, продемонстрировав отсутствие корреляции между грамматической отмеченностью и семантикой. Сам Хомский однозначно формулирует эту интенцию в одной из работ [13, с. 117]. Действительная интерпретация этой фразы, которая учитывала бы ее прагматику, должна осуществляться исключительно в этом контексте, - в отличие от всех других контекстов, предлагаемых интерпретаторами, лишь этот контекст является реальным.

На это можно было бы возразить, что фраза Хомского - это лингвистический пример, а потому поиск контекста или контекстов, в которых эта фраза оказывается приемлемой, представляет собой нормальную процедуру, которой подвергается значительная часть примеров, искусственно сконструированных лингвистами. Действительно, такие примеры качественно отличаются от обычных высказываний, что позволяет охарактеризовать их как псевдовысказывания [8]. Однако специфика псевдовысказываний определяется как раз контекстом их создания и целями, которые они преследуют: иллюстрацией языкового явления, учебными или мнемотехническими потребностями (ср. фразу Цыган на цыпочках стоит и цыц цыпленку говорит, облегчающую запоминание исключений из правила, требующего употребления буквы и после буквы ц), имитацией иностранной речи, языковой игрой и т. д. (эти функции анализируются в упомянутой статье Б. Ю. Нормана). Поэтому анализ таких предложений должен заключаться не в поиске контекста, в котором они были бы уместны, а в анализе контекстов, в которых они были созданы, с учетом целей, для которых они были созданы.

Нахождение контекстов, в которых фраза Хомского могла бы появиться, не может служить основанием для ответа на вопрос о смысле этой фразы, так как эта процедура не дает ее однозначной интерпретации, - интерпретации оказываются и недостаточно определенными, и множественными. Реальная же интенция создания этой фразы позволяет если не придать этой фразе осмысленность, то однозначно установить ее целесообразность и тем самым объяснить ее появление.

Уже эти два примера позволяют поставить вопрос о том, какие причины побуждают носителей языка искать и находить смысл в высказываниях, которые изначально создаются как лишенные смысла.

Представляется, что такое интерпретационное поведение можно рассматривать как «побочный эффект» презумпции осмысленности. Суть презумпции осмысленности очень четко сформулировал В.Б. Касевич: «семантизация - первое, что пытается осуществить носитель языка при речевосприятии, ибо всегда исходит из презумпции осмысленности воспринимаемого» [2, с. 49], «любое речевое произведение человек сначала пытается интерпретировать как осмысленное, подыскивая для него ту или иную семантическую интерпретацию» [2, c. 267]. Однако сама по себе презумпция осмысленности, в свою очередь, также нуждается в объяснении. Поэтому позволим себе уточнить вопрос, сформулировав его следующим образом: какие внешние по отношению к интерпретативной деятельности говорящего причины побуждают носителей языка искать смысл в высказываниях, которые с первого взгляда воспринимаются как лишенные смысла?

Анализ показывает, что у поиска смысла в высказываниях, которые кажутся бессмысленными, есть абсолютно веские основания, которые следует искать в сущности коммуникативных процессов.

1. Довольно часто мы придерживаемся представления о том, что любое высказывание абсолютно точно и корректно выражает мысль или передает информацию, хотя это представление вряд ли может быть принято всерьез. Вступая в коммуникацию, мы должны учитывать, что наш собеседник по разным причинам может выражать свои мысли неточно, приблизительно, небрежно, допускать ошибки, говорить неотчетливо и т.д. Заинтересованность в теме и самом общении, физическое и эмоциональное состояние, желание уклониться от контакта или скрыть информацию могут оказать влияние на то, каким образом некто участвует в нем в активной роли отправителя.

Другой важный момент, касающийся отправителя сообщения, состоит в языке, который он использует. Как справедливо пишет Ф. Росси-Ланди, слова на незнакомом языке не несут для нас конкретного смысла, одна- 
ко все равно воспринимаются нами как значащие, и мы вряд ли назовем их абсурдными [21, р. 142]. Другими словами, в ситуации восприятия слов на неизвестном языке срабатывает презумпция осмысленности. Контекст сопоставления абсурдных или бессмысленных высказываний с высказываниями на незнакомом языке представляется важным, так как странность или непонятность некоторого высказывания может быть объяснена со ссылкой на использование отправителем особого «языка» (в самом широком понимании), который интерпретатору не известен. Впрочем, этот момент можно в равной степени отнести и к измерению языковой компетенции адресата сообщения.

2. Другой важный момент состоит в том, что адресат может неправильно понять предназначенное ему высказывание в силу факторов, связанных с ним лично (невладения языком, недостаточных знаний, неспособности выявить вложенный смысл, невнимательности и т.д.) и независимо от действия других факторов, то есть уже упомянутых погрешностей автора сообщения, а также наличия помех. Адресат, ведущий себя в коммуникации рационально, не может исключать этой возможности и не может не корректировать свое поведение с ее учетом.

В этом отношении показательна дискуссия вокруг «бессмысленных» надписей на античных вазах. На дошедших до нас вазах имеется некоторое количество надписей, которые невозможно идентифицировать как слова или выражения древнегреческого языка, причем число таких надписей составляет примерно треть от всего числа надписей. Одно из хорошо аргументированных объяснений состоит в том, что авторы росписей далеко не всегда были грамотными, а потому часто механически копировали надписи на других вазах; в процессе такого копирования они не только допускали ошибки, но и копировали уже искаженные другими мастерами или даже бессмысленные надписи (см., например, [16; 17]).

Однако было высказано не менее убедительное предположение, что если не все, то очень значительная часть надписей может быть интерпретирована как «скифские» (негреческие, «варварские») имена [19], или высказывания на других языках, переданные средствами древнегреческого письма [15, р. 193-203]. С. Чарини также упоминает другие версии, в частности, передачу посредством букв нот мелодий [15, р. 188-193] или «сверхъестественное» происхождение этих конструкций, репрезентирующих речь богов или даймонов [15, р. 203-214].

Приведенный пример, несомненно, весьма специфичен, поскольку связан с интерпретацией надписей, которые выполнены на языке, не только не родном для интерпретаторов, но и древнем, - исчерпывающими или хотя бы достаточными знаниями об этом языке и той культурной ситуации, в которой он функционировал, мы не располагаем и располагать не можем. Однако и попытки реконструировать контекст, который оправдал бы создание «бессмысленных» надписей, и множественность конкурирующих объяснений обнаруживают высокое родство с контекстами интерпретаций как стихотворения Крученых, так и фразы Хомского. Даже гипотеза, в соответствии с которой надписи были выполнены неграмотными мастерами, не позволяя дать интерпретацию этих надписей, все же правдоподобно объясняет и убедительно обосновывает условия их появления.

3. Наконец, восприятие сообщения предполагает его «очищение» от помех, которые препятствуют адекватному восприятию сообщения. В работах Р.Х. Уили [24; 25] на материале коммуникации животных было показано, что шум существенно влияет на эволюцию коммуникативных средств, определяя выбор канала передачи информации, отчетливость сигнала, допустимые уровни его интенсивности, степень избыточности и т.д. Некоторые аспекты сигнала становятся значимыми с точки зрения взаимодействия между особями. Так, адекватность интенсивности сигнала свойствам среды (например, достаточная, но не избыточная громкость голоса), обычно рассматривается как показатель «честности» коммуникативного поведения.

Обращение к фактору шума в обсуждаемом контексте представляется уместным, так как принятие сообщения за шум, будучи несомненной крайностью, возможно. Это также делает необходимыми усилия адресата, направленные на дополнительный контроль того, как он интерпретирует сигналы.

Эти соображения показывают, насколько необходимым даже в повседневной коммуникации является самоконтроль интерпретатора при восприятии высказываний и сообщений. Поскольку коммуникация в подавляющем большинстве случаев нацелена на достижение взаимопонимания, становится понятным поведение адресата, который заведомо подходят к любому сообщению как к осмысленному. Такое поведение является «подстраховкой», которая гарантирует, что значимая информация не будет проигнорирована.

Впрочем, если некто производит бессмысленное или абсурдное высказывание намеренно, адресат все-таки может задаться вопросом, почему отправитель так поступает. Имея дело с речевой продукцией, мы всегда подразумеваем, что она реализует некоторые разумные, а потому постижимые намерения. Даже ссылка на состояние автора высказывания (наличие у него психических или физиологических нарушений, его нахождение в измененном состоянии сознания из-за воздействия психоактивных веществ и т.п.), не придавая высказыванию смысла, создает убедительную рамку, объясняющую 
возникновение данного высказывания.

Предложенное обоснование презумпции осмысленности не способно объяснить все механизмы, обеспечивающие приписывание смысла некоторому высказыванию. Не менее важную роль играют наличие у высказывания признаков и свойств, которые хотя бы поверхностно (формально) позволяют идентифицировать его как высказывание: возможность выделения слов или подобных им структур (в том числе на основе чисто фонетических и/ или графических свойств), наличие грамматических маркеров, наличие информации о ситуации порождения высказывания и т.д. Однако высказанные соображения позволяют сделать некоторые значимые выводы.

Всякая коммуникация сопряжена с действием факторов, которые препятствуют адекватному извлечению смысла из осмысленного высказывания, в результате чего осмысленное высказывание может быть воспринято как бессмысленное. Презумпция осмысленности как бы предохраняет получателя от неверной оценки высказывания, с которым он имеет дело, и препятствует его поспешной «отбраковке». Эту установку вряд ли можно считать исключительно продуктом культуры - внимание к другому обосновано внутривидовой кооперацией, а также контекстом совместной деятельности, которая может быть и часто бывает жизненно важной и даже способствующей выживанию. Поиск смысла в высказы- ваниях, которые планируются и создаются как заведомо бессмысленные, с этой точки зрения правомерно рассматривать как своего рода «побочный эффект» презумпции осмысленности, который, впрочем, выходит далеко за пределы самоконтроля, предотвращающего возможную интерпретационную ошибку.

Для наук языкового цикла принципиальным представляется то, что в коммуникативных феноменах, реализующих данный «побочный эффект», очень ярко проявляется действие общих интерпретационных механизмов. Так, реакции на фразу Хомского демонстрируют, что одним из таких механизмов является реконструкция гипотетического контекста, в котором некоторое высказывание обретает смысл. При этом приписывание смысла изначально бессмысленному высказыванию предполагает полное отрицание контекста, в котором данное высказывание было порождено (включая отрицание намерений его автора), и создание иного, воображаемого контекста, в котором данное высказывание оказывается если не осмысленным, то хотя бы вероятным, а потому приемлемым. Доказательством этому служит то, что интерпретации и стихотворения Крученых, и фразы Хомского осуществляются в противоречии с намерениями, эксплицитно и однозначно заявляемыми их авторами. Можно предположить, что подобные процессы происходят в сознании интерпретаторов любых высказываний, хотя в большинстве ситуаций они не могут быть замечены.

\section{ЛИТЕРАТУРА}

1. Голубева И.В., Кравченко М.А., Кравченко О.В. Явления языкового абсурда: металингвистические, когнитивно-дискурсивные и семиотические аспекты (на материале русскоязычных и франкоязычных художественных текстов). Ростов-н/Д.: Рост. гос. ун-т путей сообщения, 2010. 181 с.

2. Касевич В.Б. Семантика. Синтаксис. Морфология. — М.: «Наука», Главная редакция восточной литературы, 1988. 309 с.

3. Клецкая С.И. Авто- и метакомментарии А. Крученых к стихотворению «дыр бул щыл...» // Известия Волгоградского гос. пед. ун-та. 2020. № 9 (152). С. $151-157$.

4. Клецкая С.И. К вопросу о стратегиях семантизации бессмысленного высказывания (на материале интерпретаций «дыр бул щыл» А. Крученых) // Мир науки. Социология, филология, культурология. 2020. Т. 11. № 3. С. 15.

5. Крученых А. Помада / Рис. М. Ларионова. М.: Изд-во Г.Л. Кузьмина и С.Д. Долинского, [1913]. URL: http://elib.shpl.ru/ru/nodes/3180-kruchenyh-a-epomada-m-1913

6. Миллер Дж.А. Образы и модели, уподобления и метафоры // Теория метафоры / Вступ. ст. и сост. Н.Д. Арутюновой. М.: Прогресс, 1990. С. $236-283$.

7. Новикова В.Ю. Семантика абсурда. Краснодар Кубан. гос. ун-т, НИИ лингвистики, 2005. 149 с.

8. Норман Б.Ю. Псевдовысказывания как лингвистический феномен (на материале славянских языков) // Вестник Московского ун-та. Сер. 9. Филология. 2010. № 1. С. 32-53.

9. Успенский Б.А. Язык и коммуникационное пространство. М.: URSS. 2007. 320 с.

10. Фещенко В.В. Можно ли понимать, не понимая? Абсурдистский текст как пограничье между смыслом и бессмыслицей // Сибирский филологический журнал. 2009. № 4. 102-109.

11. Фуко М. Археология знания. Киев: Ника-Центр, 1996. 208 с.

12. Хомский Н. Аспекты теории синтаксиса. М.: Изд-во МГУ, 1972. 237 с.

13. Хомский Н. Несколько методологических замечаний о порождающей грамматике // Вопросы языкознания. 1962. № 4. С. 110-122.

14. Якобсон Р.О. Взгляды Боаса на грамматическое значение // Якобсон Р.0. Избранные работы. М.: Прогресс, 1985. С. $231-238$.

15. Chiarini S. The So-called Nonsense Inscriptions on Ancient Greek Vases: Between Paideia and Paidiá. Leiden, Boston: Brill, 2018. xiv, 543 p.

16. Immerwahr H.R. Aspects of literacy in the Athenian ceramicus // Kadmos. Vol. 46. 2007. № 1-2. P. 153-198.

17. Immerwahr H.R. Observations on writing practices in the Athenian ceramicus // Studies in Greek epigraphy and history in honor of Stefen V. Tracy. Pessac: Ausonius Éditions, 2010. P. 107-122. URL: https://books.openedition.org/ausonius/2147 (дата обращения: 03.06.2021). 
18. Jahn M. «Colorless Green Ideas Sleep Furiously»: A Linguistic Test Case and Its Appropriations // Literature and Linguistics: Approaches, Models, and Applications: Studies in Honour of Jon Erickson. Trier: Wissenschafter Verlag, 2002. P. 47-60.

19. Mayor A., Colarusso J., Saunders D. Making Sense of Nonsense Inscriptions Associated with Amazons and Scythians on Athenian Vases // Hesperia: The Journal of the American School of Classical Studies at Athens. Vol. 83. 2014. № 3. P. 447-493.

20. Odell S.J. Nonsense // Metaphilosophy. 1971. Vol. 2. № 1. P. 44-49.

21. Rossi-Landi F. On Absurdity // Rossi-Landi F. Between sign and non-sign. Amsterdam: John Benjamins B. V., 1992. P. 131-156.

22. Stewart S. Nonsense. Aspects of intertextuality in folklore and literature. Baltimore, London: The John Hopkins University Press, 1989. xi, $228 \mathrm{p}$.

23. Uslu M.E. Semiocide: An introduction to semiotics of destruction of the meaningful // Sign Systems Studies. 2020. Vol. 48. № 2-4. P. $224-245$.

24. Wiley R.H. How noise determines the evolution of communication // Animal Behaviour. Vol. 124. P. 307-313.

25. Wiley R.H. Noise matters: The evolution of communication. Cambridge, London: Harvard University Press, 2015. xiv, 502 p.

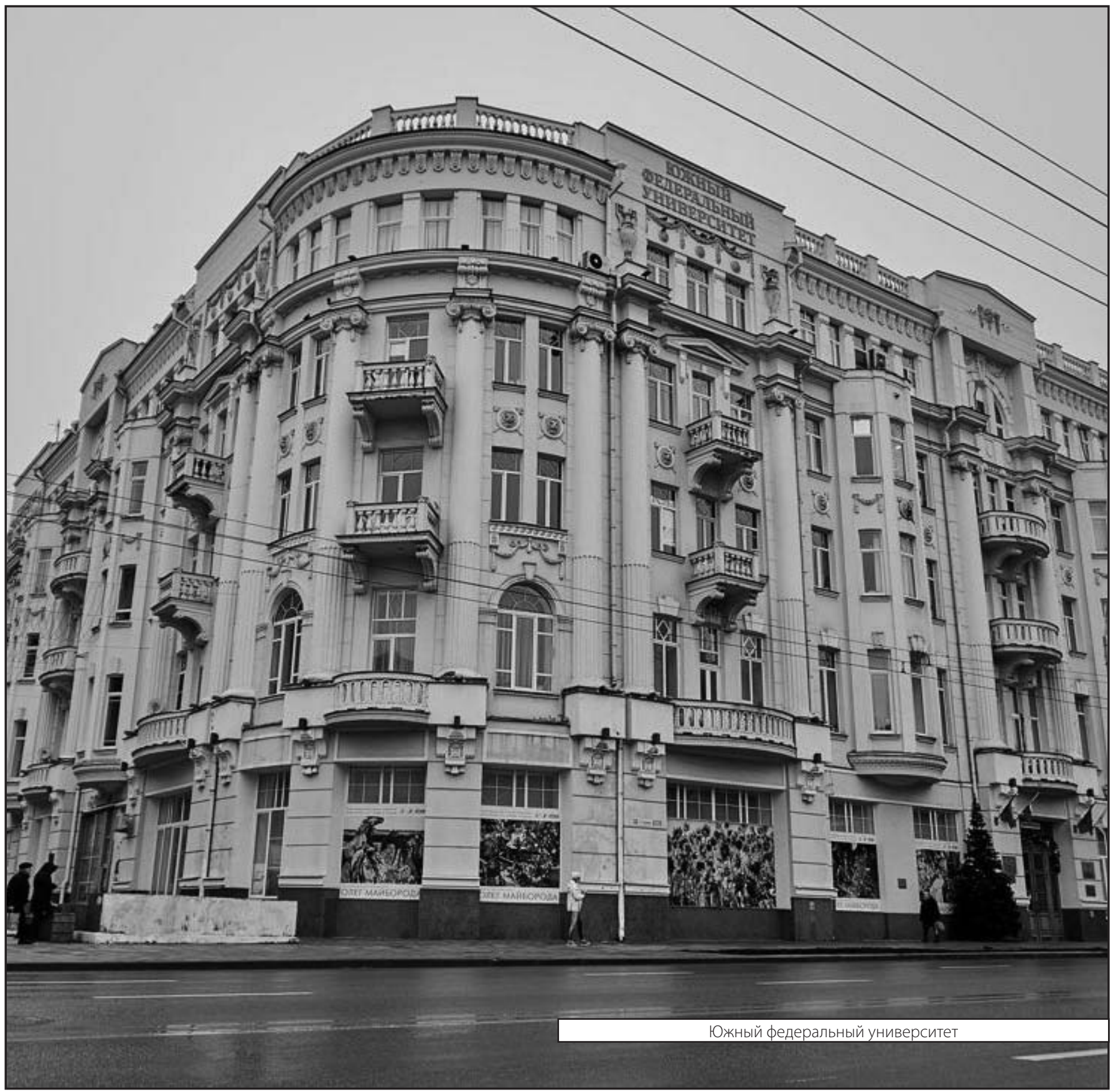

